\title{
Localization of the Site of Recombination in
}

\section{Formation of the Lepore Boston Globin Gene}

\author{
Michael Baird, Helen Schreiner, Catherine Driscoll, and Arthur Bank, \\ Columbia University College of Physicians \& Surgeons, Department of \\ Medicine, Department of Human Genetics and Development, and Department \\ of Pediatrics Hammer Health Sciences Center, New York 10032
}

A BSTRACT The site of crossover between the $\delta$ - and $\beta$-globin gene sequences resulting in Lepore Boston globin gene formation has been localized at the DNA level. Probes specific for detecting the intervening sequences (IVS) of the $\delta$ - and $\beta$-globin genes were used to map the origin of cellular DNA fragments of a patient homozygous for hemoglobin Lepore Boston. Restriction endonuclease analysis and hybridization of this DNA to IVS specific probes show that most, if not all, of the large intervening sequences (IVS 2) in Lepore DNA are derived from the $\beta$-globin gene IVS 2 . In addition, the crossover occurs in a region of DNA in which the $\delta$ - and $\beta$-genes have almost complete nucleotide homology, and might be expected to pair most tightly during meiosis.

\section{INTRODUCTION}

Hemoglobin Lepore Boston is an abnormal hemoglobin, produced in decreased amounts that contains a Lepore globin chain with a $\delta$-globin amino acid sequence at its $\mathrm{N}$-terminus, and a $\boldsymbol{\beta}$-globin amino acid sequence at its C-terminus. In Lepore Boston globin, amino acid 87 is $\delta$, and amino acid 116 is $\beta$, indicating that the crossover event leading to the formation of this fusion protein has occurred between these two positions (1). Gene mapping by restriction enzyme analysis and hybridization to radiolabeled $\beta$-complementary DNA (cDNA) probe indicates that the Lepore Boston gene is indeed a fusion gene containing $\delta$ specific nucleotide sequences at its $5^{\prime}$ end and $\beta$ at its $3^{\prime}$ end (Fig. 1) (2,3). Direct nucleotide sequencing of cloned $\delta$ - and $\beta$-globin genes $(4,5)$ shows that both possess two identically positioned intervening sequences (IVS) ${ }^{1}$ interrupting the coding sequences: a

Received for publication 24 April 1981 and in revised form 18 May 1981.

${ }^{1}$ Abbreviation used in this paper: IVS, intervening sequences of the $\delta$ - and $\beta$-globin gene. small IVS (IVS 1) between codons 30 and 31 , and a larger IVS (IVS 2) between codons 104 and 105. Because IVS 2 lies within the region of the recombination producing Lepore Boston, the composition of IVS 2 in the Lepore fusion gene could be entirely $\beta$-IVS, $\delta$-IVS, or a combination of the two. Divergence of the $\delta$ - and $\beta$-IVS 2 nucleotide sequences, availability of specific probes for these regions, and knowledge of the nucleotide sequence of the $\delta$ - and $\beta$-genes have permitted analysis of this question. This report localizes the site of transition from $\delta$ - to $\beta$-sequence to a region of intense nucleotide homology $5^{\prime}$ to the Asu 1 site in the IVS 2 of the $\beta$-globin gene.

\section{METHODS}

Preparation of cloned probes and the source of DNA. Specific probes containing $\delta$ - and $\beta$-IVS 2 nucleotide sequences were obtained either as a gift from Tom Maniatis (6) or by cloning the appropriate Bam HI/Eco RI fragments from a $\beta$-thalassemia clone (7) into $\mathrm{pBR} 322$; a 0.95 -kilobase (kb) fragment contains the $\delta$-IVS 2 and a 0.92 -kb fragment contains the $\beta$-IVS 2. A 4.4-kb Pst I cloned DNA fragment includes the $\beta$-globin structural gene plus flanking sequences. Each of these probes was isolated from their pBR 322 vectors by appropriate endonuclease digestion, and purified by sucrose density gradient centrifugation (6).

DNA from the Lepore-Boston patient studied has been previously analyzed (8). A lymphocyte cell line established from this patient was used in these experiments.

Restriction analysis. Restriction endonuclease digestion with Eco RI (Boehringer Mannheim Biochemicals, Indianapolis Ind.) and Asu I (Bio-Lab Inc., Decatur, Ga.) was performed according to the manufacturer's specifications. Transfer of DNA fragments from $\mathbf{0 . 8 \%}$ agarose (Sea Kem) to nitrocellulose filters, nick translation of probes $\left(1-8 \times 10^{8} \mathrm{cpm} / \mu \mathrm{g}\right)$, hybridization of filters, and radioautography were performed as described previously $(2,9)$.

\section{RESULTS}

When normal DNA is digested with Eco RI and hybridized to a nick translated 4.4-kb Pst I probe, four bands $5.2,3.6,2.25$, and $1.75 \mathrm{~kb}$ in size are seen. (Fig. 1 ) 
A.
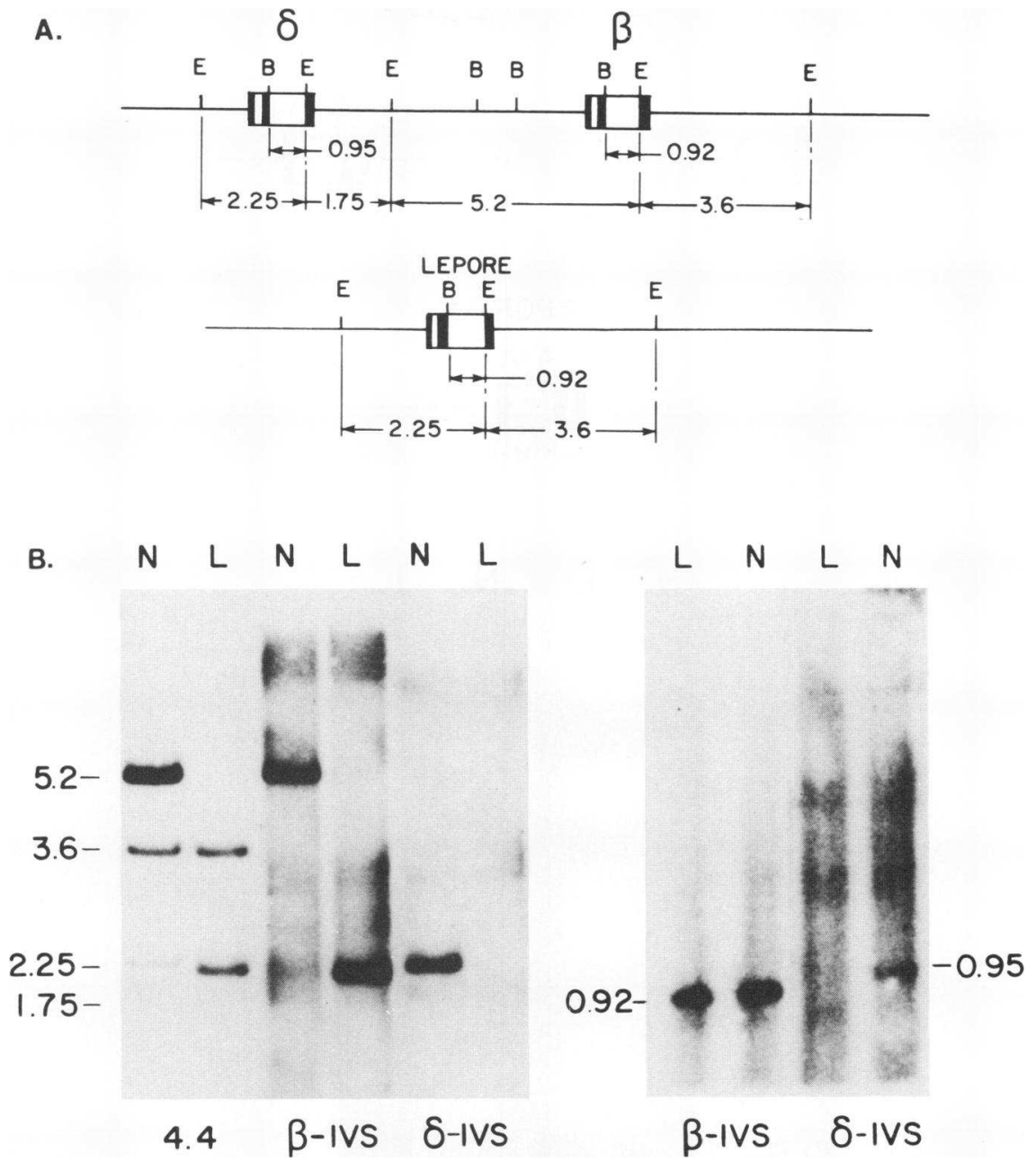

FIgURE 1 Restriction enzyme analysis of normal (N) and Lepore (L) DNA with Eco RI (E) and Bam HI (B). A. Restriction map with fragment sizes indicated in kb. The black areas in the rectangles are the coding regions, and the clear areas the IVS. B. Radioautographs of hybridization patterns of normal and Lepore DNA digested with Eco RI (six at left) and with Eco RI and Bam HI (four at right). The ${ }^{32} \mathrm{P}-4.4-\mathrm{kb}$ Pst I probe reveals the expected four fragments in normal DNA and two in Lepore DNA. A ${ }^{32} \mathrm{P}-\beta$-IVS 2 probe yields only a $5.2-\mathrm{kb}$ band in normal DNA, and a $2.25-\mathrm{kb}$ band in Lepore DNA. A ${ }^{32} \mathrm{P}-\delta$-IVS 2 probe produces only a $2.25-\mathrm{kb}$ band with normal DNA, and no detectable hybridization with Lepore DNA. Both normal and Lepore DNA, digested with both Eco RI and Bam HI, display $0.92-\mathrm{kb}$ fragments when probed with ${ }^{32} \mathrm{P}-\beta$-IVS 2 . No hybridization is seen with ${ }^{32} \mathrm{P}-\delta$-IVS 2 (second from right with Lepore DNA).

$(2,9)$. The $1.75-\mathrm{kb}$ fragment is poorly seen, presumably because of the limited homology of the $3^{\prime} \beta$-flanking region (represented in the probe) and the $3^{\prime}$ end of the $\delta$-gene (represented in the 1.75 -kb fragment). The 5.2and 2.25-kb Eco RI restriction fragments have been shown to contain $\beta$ - and $\delta$-IVS 2 , respectively $(2,3)$. Hybridization with the $\delta$ - and $\beta$-IVS 2 probes to these fragments was used to demonstrate their specificity. When normal DNA is cleaved with Eco RI, and hybridized with the ${ }^{32} \mathrm{P}-\beta$-IVS 2 probe, only the $5.2-\mathrm{kb}$ fragment is seen; ${ }^{32} \mathrm{P}$ - $\delta$-IVS 2 probe hybridizes only to the 2.25-kb fragment (Fig. 1B).
To determine whether the Lepore Boston gene contains $\delta$-IVS $2, \beta$-IVS 2 , or both, a similar experiment was performed with Lepore Boston DNA. When DNA from a patient homozygous for $\mathrm{Hb}$ Lepore Boston is digested with Eco RI, two fragments hybridize to the 4.4-kb Pst I probe, 3.6 and $2.25 \mathrm{~kb}$. The 2.25 -kb fragment contains the Lepore-IVS 2 , and hybridizes to the $\beta$-IVS 2 probe, but not with the $\delta$-IVS 2 probe (Fig. 1B). Double digestion of normal and Lepore DNA with Bam HI and Eco RI produces identical 0.92-kb fragments hybridizing to the $\beta$-IVS 2 probe, but only the normal DNA shows a $0.95 \mathrm{~kb}$-fragment when hybridizing to the $\delta$ - 

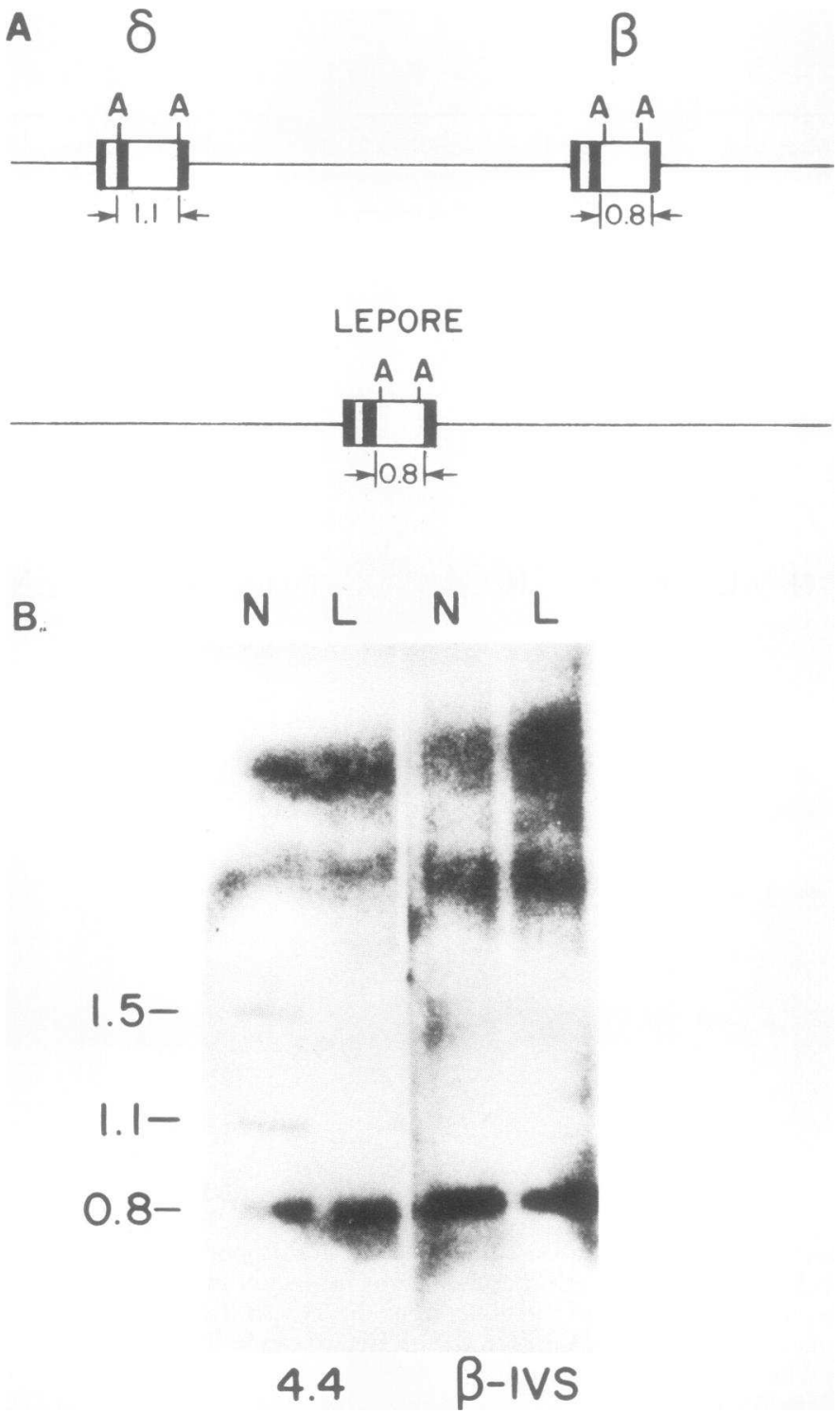

FIGURE 2 Restriction enzyme analysis of normal (N) and Lepore (L) DNA with Asu I. A. Restriction map of Asu I sites within IVS 2 normal $\delta$ - and $\beta$-globin genes, and in the Lepore gene. Other Asu I sites occurring within and around the $\delta-, \beta-$, and Lepore genes are not shown. B. Radioautographs of normal and Lepore DNA cleaved with Asu I. Normal DNA (at left) hybridizes to a ${ }^{32} \mathrm{P}-4.4$-Pst I probe and shows three bands $1.5,1.1$, and $0.8 \mathrm{~kb}$ in size while Lepore shows the $0.8 \mathrm{~kb}$ only (second from left). Only 0.8 -kb fragments are seen when both normal and Lepore DNA are hybridized to ${ }^{32} \mathrm{P}-\beta$-IVS 2 probe (at right). No hybridization is seen when Lepore DNA is hybridized to $\delta$-IVS 2 probe (data not shown). The hybridization in the region above $1.5 \mathrm{~kb}$ is nonspecific and not reproducible.

IVS 2 probe; there is again no hybridization of Lepore DNA to the $\delta$-IVS 2 probe (Fig. $1 B$ ).

To further determine the composition of the IVS 2 of Lepore, normal and Lepore DNA were digested with the enzyme Asu I, and hybridized with the 4.4-kb Pst I, $\delta$-IVS, and $\beta$-IVS 2 specific probes. An Asu I site is present 10 nucleotides from the $5^{\prime}$ end of the $\beta$-IVS 2 , but not at a comparable site in the $\delta$-IVS 2 .
A 0.8-kb fragment would be expected if the $5^{\prime}$ end of the Lepore IVS 2 is derived from $\beta$-IVS 2 , and a larger fragment if the IVS 2 of Lepore is derived from $\delta$-IVS 2 (Fig. 2). Fig. 2B shows that identical 0.8-kb fragments hybridize with the $\beta$-IVS 2 probe in normal and Lepore DNA digested with Asu I, consistent with the presence of identical sequences at the $5^{\prime}$ end of IVS 2 in the $\beta$ - and Lepore genes. Two additional Asu I 
digested fragments are seen in normal DNA hybridized to the $4.4-\mathrm{kb}$ Pst I probe presumably representing sequences between the $\delta$ - and $\beta$-globin gene (Fig. 2). The absence of these fragments in Asu I digested Lepore DNA (Fig. 2B) presumably reflects the deletion of the region between the $\delta$ - and $\beta$-globin genes in the Lepore Boston gene. No hybridization is seen when Asu I digested Lepore DNA is hybridized to $\delta$-IVS 2 probe.

\section{DISCUSSION}

The use of probes specific for the $\delta$-IVS 2 and $\beta$-IVS 2 permits analysis of the origin of IVS 2 in the Lepore Boston gene. Although the Bam HI/Eco RI fragments containing the $\delta$-IVS 2 and $\beta$-IVS 2 have 19 coding sequence nucleotides in common at the $5^{\prime}$ end and 48 nucleotides at the $3^{\prime}$ end, no crosshybridization is observed at the stringency of hybridization and washing used (Fig. 1B). The observation that the Lepore 2.25-kb fragment hybridizes only with the $\beta$-IVS 2 and not the $\delta$-IVS 2 probe indicates that the Lepore IVS 2 contains predominantly $\beta$-IVS 2 sequences, and no $\delta$-IVS 2 sequences at the level of sensitivity afforded by the IVS 2 probes.

Finding a 0.8-kb Asu I fragment in Lepore DNA that hybridizes uniquely with $\beta$-IVS 2 probe indicates that the $5^{\prime}$ end, and, thus, virtually the entire IVS 2 of the Lepore Boston gene is derived from $\beta$-IVS 2 . The $\delta$-IVS 2 and the $\beta$-IVS 2 differ in only two nucleotides between the Asu I site at the $5^{\prime}$ end of the $\beta$-IVS 2 and the 3 ' end of the second structural coding region (Fig. 3). The near identity of nucleotide sequence in the $\delta$ - and $\beta$-globin genes between the Asu I site at the 5 ' side of the $\beta$-IVS 2 and the nucleotides coding for $\delta$-globin amino acid 87 (Fig. 3) precludes further definition of the crossover site by restriction enzyme analysis. The results indicate that the site of recombination between $\delta$ - and $\beta$-globin genes to form Lepore Boston occurs in a region of very high nucleotide homology, and not within IVS 2 sequences which are much more divergent in the $\delta$ - and $\beta$-genes. Thus, the recombination event appears to have occurred by nucleotide homology with crossing over at meiosis between misaligned $\delta$ - and $\beta$-genes. Whether other sites of homology, more distal to this region, provide additional stability favoring recombination at this site remains unknown.

The sites of crossover in the formation of other Lepore globin genes are also in regions of intense homology between the $\delta$ - and $\beta$-genes (10). In Lepore Hollandia, the crossover from $\delta$ - to $\beta$-sequence is between codons 22 and 50 , a region of over $90 \%$ homology, whereas in Lepore Baltimore the crossover is between codons 50 and 86 , a region of $97 \%$ homology. Potential sites of crossover in the formation of the anti-Lepore globin genes are also included in regions with strong nucleotide homology between the $\delta$ and $\beta$-genes (10).

The reasons for the underproduction of Lepore Boston globin are not clear. A processing defect arising from a mixed IVS 2 containing $\delta$ - and $\beta$-IVS 2 sequences seems unlikely from the present data. A Lepore-globin mRNA precursor with a $\delta$-IVS 1 and a $\beta$-IVS 2 may be unstable or unable to be processed efficiently. From our data, a $\beta$-IVS 2 is probably insufficient for synthesis of Lepore globin at a level comparable to normal $\beta$-globin. The normal $\delta$-globin gene containing a $\delta$-IVS 1 is also associated with decreased production of its product, $\delta$-globin. Miyada globin, an anti-Lepore $(\beta \delta)$ fusion gene product, is also produced in low amounts despite the presence of $5^{\prime} \beta$ flanking sequences presumably containing regulatory sequences identical to those of the normal $\beta$-globin gene (11). It is of interest that this gene also contains a $\delta$-IVS 1 since the crossover occurs $5^{\prime}$ to codon 22 , and IVS 1 is between codons 30 and 31 . Thus, genes such as normal $\delta$, Lepore, and anti-Lepore, containing $\delta$-IVS 1 sequences, all result in decreased synthesis of their globin products, suggesting the potential importance of the origin of IVS 1 in the optimal transcription or processing of their gene products. The presence

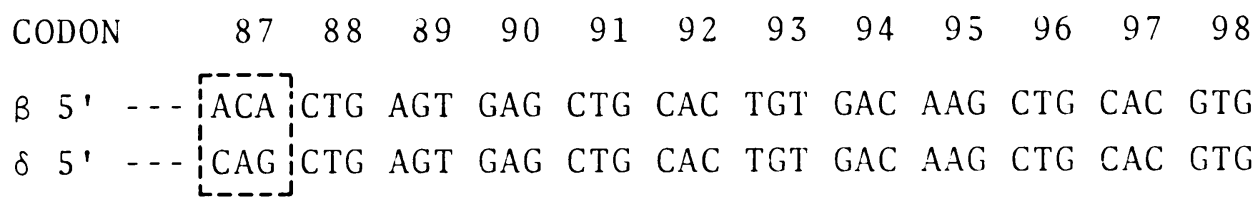

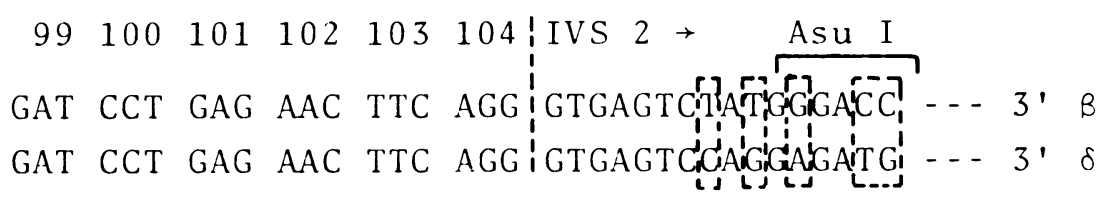

Figure 3 Nucleotide sequences in the $\delta$ - and $\beta$-globin genes between codon 87 and the Asu I site. The differences in sequence are indicated by dotted lines. 
of an intact $\beta$-IVS 1 might be required to ensure optimal transcription and processing of $\beta$-like globin genes. The recent finding of a single base change within the $\beta$-IVS 1 in a cloned gene associated with decreased $\beta$-globin mRNA and globin synthesis in a patient with $\beta^{+}$-thalassemia also suggests the significance of an intact $\beta$-IVS 1 in the regulation of $\beta$-globin gene expression (12). While $\delta$ - and $\beta$-IVS 2 sequences are quite divergent, $\delta$ - and $\beta$-IVS 1 sequences are quite homologous ( $>90 \%)$. It will be of great interest to assess the effects on function of the few differences in the nucleotide sequence of $\delta$ - and $\beta$-IVS 1 using in vitro or in vivo assay systems that measure globin mRNA transcription and processing with either natural cloned globin genes or recombinant DNA molecules containing these sequences (13).

\section{ACKNOWLEDGMENTS}

We thank Una Collins for preparing this manuscript.

This work has been supported by National Institutes of Health grant AM-25274, National Science Foundation grant 24120, Cooley's Anemia Foundation grant 312-2581, March of Dimes Birth Defects Foundation grant NF-1-664, and New York Community Trust grant. Dr. Baird and Dr. Driscoll are postdoctoral fellows supported by National Institutes of Health grants AM-07373 and GM-07419, respectively.

\section{REFERENCES}

1. Baglioni, C. 1962. The fusion of two peptide chains in hemoglobin Lepore and its interpretation as a genetic deletion. Proc. Natl. Acad. Sci. U. S. A. 48: 1880-1886.

2. Mears, J. G., F. Ramirez, D. Leibowitz, and A. Bank. 1978. Organization of human $\delta$ and $\beta$ globin genes in cellular DNA and the presence of intragenic inserts. Cell. 15: 15-23.

3. Flavell, R. A., J. M. Kooter, E. DeBoer, P. F. R. Little, and R. Williamson. 1978. Analysis of the human $\delta \beta$ globin gene loci in normal and $\mathrm{Hb}$ Lepore DNA: direct determination of gene linkage and intergenic distance. Cell. 15: 25-41.

4. Spritz, R. A., J. K. deRiel, B. G. Forget, and S. M. Weissman. 1980. Complete nucleotide sequence of the human $\delta$ globin gene. Cell. 21: 639-646.

5. Lawn, R. M., A. Efstratiadis, C. O'Connell, and T. Maniatis. 1980. The nucleotide sequence of the human $\beta$ globin gene. Cell. 21: 647-651.

6. Lawn, R. M., E. F. Fritsch, R. C. Parker, G. Blake, and T. Maniatis. 1978. The isolation and characterization of linked $\delta$ and $\beta$ globin genes from a cloned library of human DNA. Cell. 15: 1157-1174.

7. Burns, A. L., S. Spence, K. Koche, F. Ramirez, J. G. Mears, H. Schreiner, C. Miller, M. Baird, D. Leibowitz, P. Giardiana, A. Markenson, and A. Bank. 1981. Isolation and characterization of cloned DNA: the $\delta$ and $\beta$ globin genes in homozygous $\beta^{+}$thalassemia. Blood. 57: 140-146.

8. Ramirez, F., J. G. Mears, U. Nudel, A. Bank, L. Luzzatto, G. DiPrisco, R. D'Avino, G. Pepe, L. Camardella, R. Gambino, R. Cimino, and N. Quattrin. 1979. Defects in DNA and globin mRNA in homozygotes for hemoglobin Lepore. J. Clin. Invest. 63: 736-742.

9. Mears, J. G., F. Ramirez, D. Leibowitz, F. Nakamura, A. Bloom, F. Konotey-Ahulu, and A. Bank. 1978. Changes in restricted human cellular DNA fragments containing globin gene sequences in the thalassemias and related disorders. Proc. Natl. Acad. Sci. U. S. A. 75: 1222-1224.

10. Bunn, H. F., B. G. Forget, and H. M. Ranney. 1977. Hemoglobinopathies, W. B. Saunders Company. Philadelphia, Pa. 12: 28-94.

11. Roberts, A. V., J. B. Clegg, D. J. Weatherall, and Y. Ohta. 1972. Synthesis in vitro of anti-Lepore hemoglobin. Nature (Lond.). 245: 23-30.

12. Spritz, R. A., P. Jagadeeswaran, P. V. Choudary, P. A. Biro, J. T. Elder, J. K. deRiel, J. L. Manley, M. L. Gefter, B. G. Forget, and S. M. Weissman. 1981. Base substitution in an intervening sequence of a $\beta^{+}$thalassemic human globin gene. Proc. Natl. Acad. Sci. U. S. A. 78: 2455-2459.

13. Chu, G., and P. A. Sharp. 1981. A gene chimaera of SV40 and mouse $\beta$ globin is transcribed and properly spliced. Nature (Lond.). 289: 278-382. 